\title{
A biweekly mode in the equatorial Indian Ocean
}

\author{
Debasis Sengupta, ${ }^{1}$ Retish Senan, ${ }^{1}$ V. S. N. Murty, ${ }^{2}$ and V. Fernando ${ }^{2}$
}

\begin{abstract}
The National Institute of Oceanography, Goa deployed moorings with several subsurface current meters at $0^{\circ}, 93^{\circ} \mathrm{E}$ (in February 2000 ) and $0^{\circ}, 83^{\circ} \mathrm{E}$ (in December 2000) in the eastern Indian Ocean. Observed meridional current at all depths has a 10-20 day (or biweekly) variability that is distinct from longer period (20-60 day) subseasonal variability. Lags between different instruments suggest the presence of groups of westward and vertically propagating biweekly waves with zonal wavelength in the range 2100 to $6100 \mathrm{~km}$. We use an ocean model forced by high resolution scatterometer wind stress to show that the observed biweekly variability is due to equatorially trapped mixed Rossby-gravity waves generated by subseasonal variability of winds. We demonstrate that quasi-biweekly fluctuations of surface meridional wind stress resonantly excite ocean waves with westward and upward phase propagation, with typical period of 14 days and zonal wavelength of 3000-4500 $\mathrm{km}$. The biweekly wave is associated with fluctuating upwelling/downwelling in the equatorial Indian Ocean, with amplitude of 2-3 meters per day located $2^{\circ}-3^{\circ}$ away from the equator. Possible reasons for eastward intensification of biweekly energy is discussed.
\end{abstract}

\section{Introduction}

Observed currents in the equatorial Indian Ocean (EqIO) have consistently shown intraseasonal variability with periods of a few days to 60 days [Schott and McCreary, 2001]. A prominent 26 day oscillation of meridional current in the western EqIO [Luyten and Roemmich, 1982] is due to mixed Rossby-gravity (MRG) waves with zonal wavelength of 1100$2000 \mathrm{~km}$ [Reverdin and Luyten, 1986; Tsai et al., 1992]. Model studies suggest that the 26 day MRG wave is generated by dynamic instability of seasonal currents [Kindle and Thompson, 1989]. The 1973-1975 weekly record from Gan Island $\left(\sim 73^{\circ} \mathrm{E}\right)[$ Knox, 1976] shows dominant 30-60 day variability of equatorial zonal current, and suggests the presence of variability with periods shorter than 20 days [McPhaden, 1982]. The observations of Schott et al. [1994] from the eastern EqIO in the 1990's gave the first clear demonstration of 10-20 day ("biweekly") variability. An array of three moorings carrying acoustic Doppler current profilers (ADCP) and rotor current meters (RCM) was deployed along $80.5^{\circ} \mathrm{E}$ south of Sri Lanka between December 1990 and March 1992. Off-equator zonal current and upper ocean zonal volume transport across this array has large fluctuations with biweekly period. An ocean general circulation model (OGCM) forced by daily NCEP reanalysis [Kalnay et al., 1996] surface winds suggests that these fluctuations of off-equator zonal transport are mainly associated with westward propagating MRG waves with 12-15 day period forced by intraseasonal fluctuations of wind stress [Sengupta et al., 2001]. Subsequent moored current meter observations (July 1993-September 1994) along $80.5^{\circ} \mathrm{E}$ from an array spanning the equator reveals a distinct 15 day spectral peak (Figure 1) in equatorial meridional current and off-equator zonal current, consistent with the meridional structure of MRG waves

\footnotetext{
${ }^{1}$ Centre for Atmospheric and Oceanic Sciences, Indian Institute of Science, Bangalore, India.

${ }^{2}$ Physical Oceanography Division, National Institute of Oceanography, Goa, India.
}

Copyright 2004 by the American Geophysical Union. 0148-0227/04/\$9.00
[Matsuno, 1966; Gill, 1982]. Apart from the suggestion of Sengupta et al. [2001] that the observed biweekly variability of zonal flow south of Sri Lanka is mainly due to wind forced MRG waves, there has been no study of the nature of biweekly variability in the EqIO.

Atmospheric variability in the tropical Indian Ocean has two dominant intraseasonal modes with 30-60 day and 1020 day (or quasi-biweekly) period [Yasunari, 1981; Krishnamurti and Ardunay, 1980; Krishnamurti et al., 1988; Goswami et al., 1998]. The 30-60 day eastward propagating Madden-Julian oscillation is the dominant mode of intraseasonal variability [Madden and Julian, 1972, 1994] in the equatorial region. The 30-60 day mode, which appear to propagate northward in summer [Sikka and Gadgil, 1980], and a westward propagating quasi-biweekly mode (QBM) largely determine the active-break cycle of the summer monsoon over the Bay of Bengal [Krishnamurti and Ardunay, 1980]. Although the existence of the QBM has been known for some time, quasi-biweekly variability over the equatorial Indian Ocean has not received much attention. The observational work of Chen and Chen [1993] on the QBM in boreal summer is based on daily FGGE data and outgoing longwave radiation (OLR). It shows that the horizontal structure of this mode consists of twin vortices, one centered near the Indian Ocean equator, and one near $18^{\circ} \mathrm{N}$. The vortices have zonal length scale of about $30^{\circ}$, and move west at $4-5 \mathrm{~m} \mathrm{~s}^{-1}$. Chatterji and Goswami [2004] have recently studied the atmospheric QBM using daily OLR and NCEP reanalysis winds at $850 \mathrm{hPa}$ and higher levels. They demonstrate that quasi-biweekly activity is present throughout the year with varying amplitude (cf. their Figures 2-4). Over the tropical central and eastern Indian Ocean and the west Pacific, the QBM is associated with twin vortices of zonal scale $30^{\circ}$ (i.e., zonal wavelength of about $6000 \mathrm{~km}$ ) and westward speed of $4.5 \mathrm{~m} \mathrm{~s}^{-1}$. Stability analysis suggests that the QBM is a convectively coupled first meridional mode equatorial Rossby wave. Chatterji and Goswami [2004] suggest that the large scale vorticity distribution causes the centre of the southern (northern) vortex of the wave to be located close to the equator during the summer (winter) monsoon, whereas the other vortex is located in the summer hemisphere.

Recent observations of equatorial currents in the eastern Indian Ocean show distinct biweekly variability. In February 


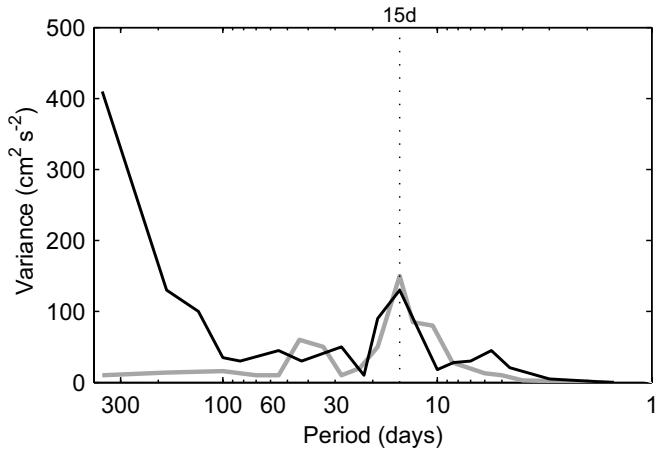

Figure 1. Spectra of $25-\mathrm{m}$ zonal current at $5^{\circ} \mathrm{N}$ (black) and meridional current at the equator (grey) along $80.5^{\circ} \mathrm{E}$ during July 1993-September 1994 (adapted from Reppin et al. [1999]). The dotted line corresponds to a period of 15 days.

2000, the National Institute of Oceanography, Goa (NIO) deployed a mooring with rotor current meters at several subsurface depths at $0^{\circ}, 93^{\circ} \mathrm{E}$ [Murty et al., 2002] under the Ocean Observing Systems programme of the Department of Ocean Development, New Delhi. NIO has since deployed two more current meter moorings at $0^{\circ}, 83^{\circ} \mathrm{E}$ and $0^{\circ}$, $76^{\circ} \mathrm{E}$. The Japanese Marine Science and Technology Cen- tre (JAMSTEC) installed a mooring with an ADCP and a TRITON surface buoy at $0^{\circ}, 90^{\circ} \mathrm{E}$ in November $2000[\mathrm{Ma}$ sumoto et al., 2002]. At the time of writing, both NIO and JAMSTEC observations are continuing. The NIO and JAMSTEC datasets show rich intraseasonal variability of equatorial currents. The most energetic zonal current $(u)$ fluctuations in the upper ocean have 30-60 day period, whereas the meridional current $(v)$ has biweekly variability [Murty et al., 2002, Y. Masumoto, personal communication] that is distinct from slower intraseasonal oscillations.

Here we investigate the nature of the biweekly variability in the equatorial Indian Ocean using the NIO observations at $0^{\circ}, 93^{\circ} \mathrm{E}$ and $0^{\circ}, 83^{\circ} \mathrm{E}$ and an OGCM forced by high resolution surface winds from a satellite-borne scatterometer. The observations and model are described in the next section. The existence of distinct biweekly variability of meridional current in the observations is established in Section 3. The model simulates the biweekly variability (but not the observed 30-60 day fluctuations of $v$ ) with reasonable accuracy at all depths upto $2000 \mathrm{~m}$. We estimate the zonal and vertical length scales of the biweekly mode from the observations, and present the first results about its space-time structure with the help of the model simulation in Section 4. We establish that the biweekly mode consists of packets of westward propagating wind forced MRG waves. Vertical phase propagation of these waves is generally, but not always, upward. They are associated with deep, offequator upwelling/downwelling. In Section 5 we show that the variability of meridional wind stress associated with the
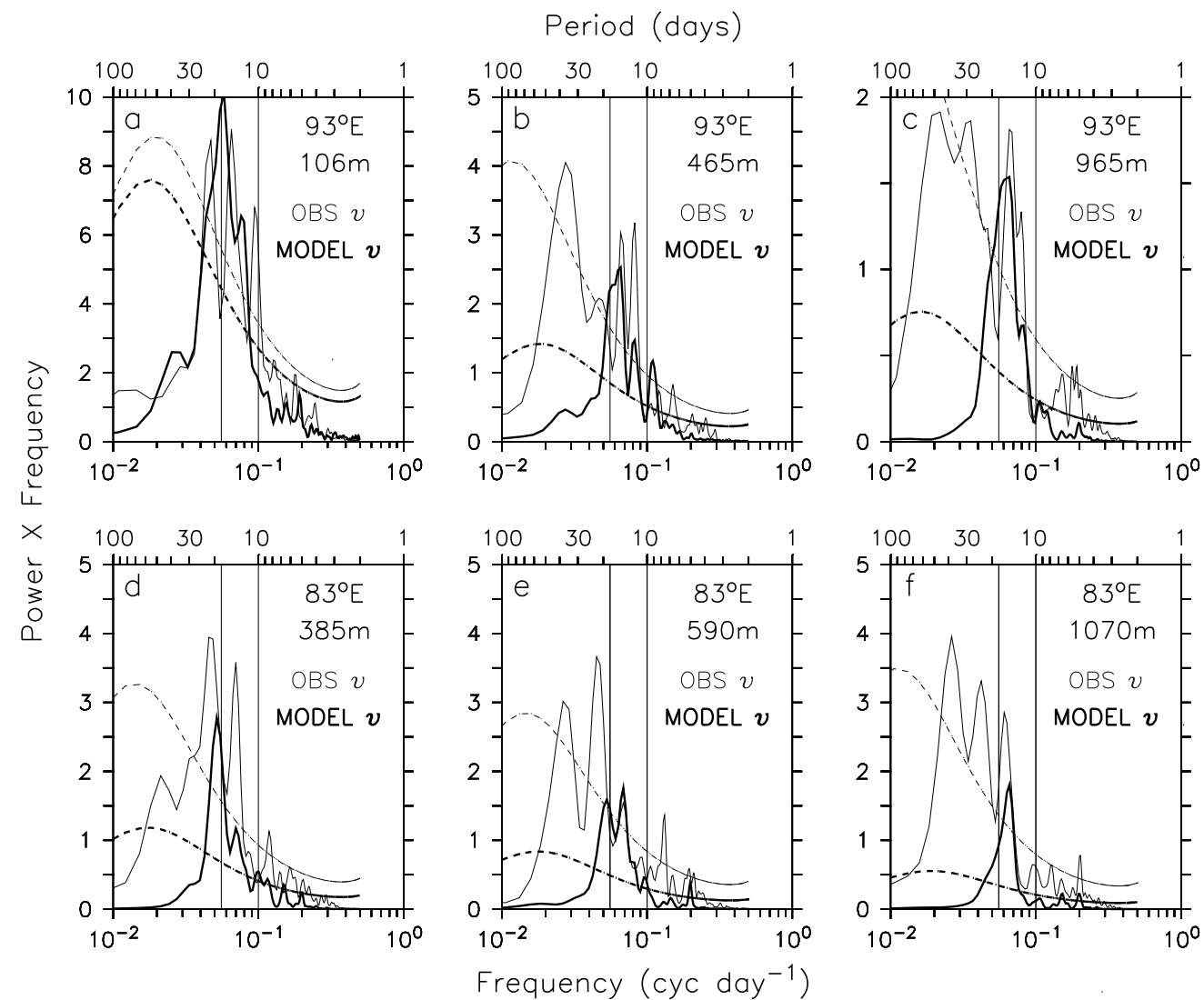

Figure 2. Variance preserving power spectra of December 2000 - December 2001 observed and model meridional velocity $(v)$. (a) Spectra of $v$ at uppermost instrument depth $0^{\circ}, 93^{\circ} \mathrm{E}$ from observations (thin) and QuikSCAT simulation (bold); the depth fluctuates between $90 \mathrm{~m}$ and $170 \mathrm{~m}$ due to mooring motion, with a mean of $106 \mathrm{~m}$; (b,c) as in (a), but for the instruments at $465 \mathrm{~m}$ and $965 \mathrm{mean}$ depth; $(\mathrm{d}, \mathrm{e}, \mathrm{f})$ as in (a) but for $0^{\circ}, 83^{\circ} \mathrm{E}$ at mean depths of $385 \mathrm{~m}, 590 \mathrm{~m}$ and $1070 \mathrm{~m}$. The dashed lines are the $95 \%$ confidence levels based on a red-noise background. Units are arbitrary, but identical across all panels. The cut-offs (10 and 18 days) of the Lanczos filter used to extract the 10-20 day mode are shown. 

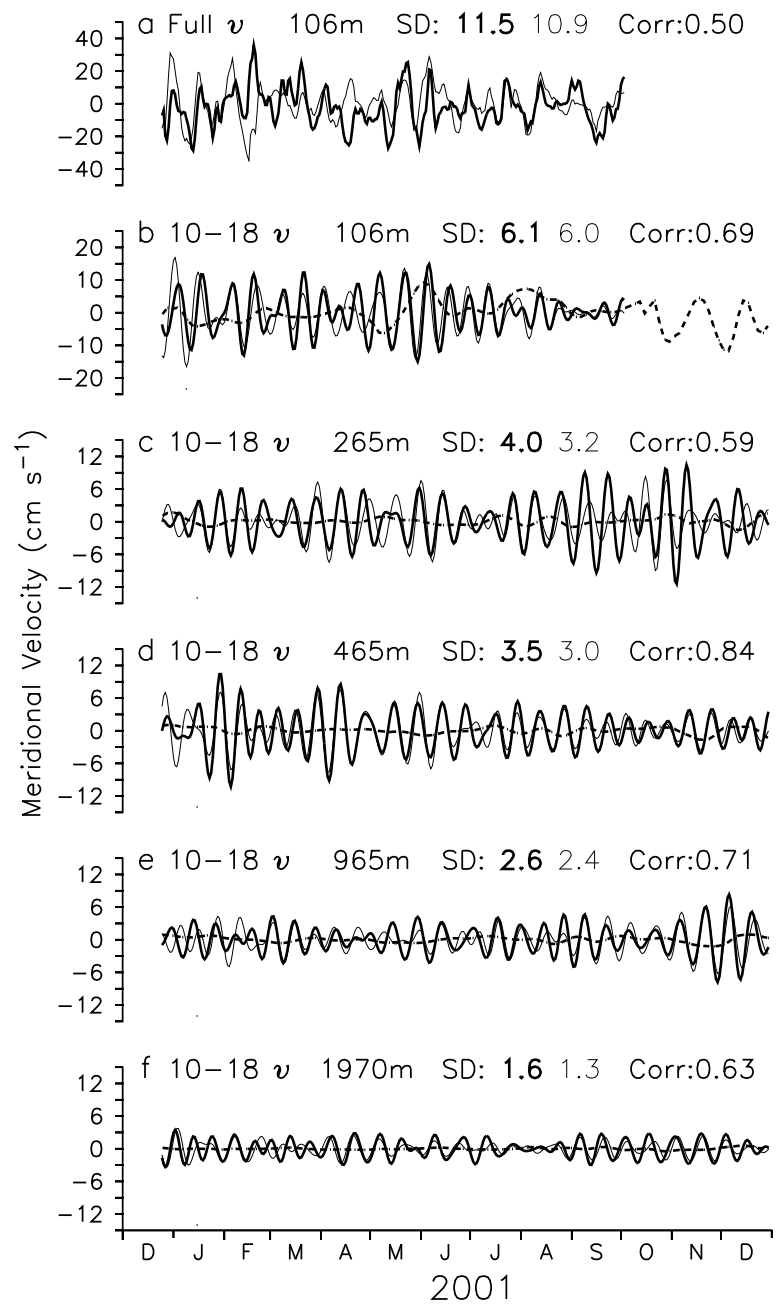

Figure 3. Comparison of observed and model $v$ at $0^{\circ} \mathrm{N}$, $93^{\circ}$ E. (a) Observed (bold) and model (thin) unfiltered $v$ at uppermost instrument depth; (b-f) observed (bold) and model (thin) 10-18 day filtered $v$; model $v$ from the seasonal run (dashed). The current meter at $106 \mathrm{~m}$ gave no data beyond October. The mean instrument depth, standard deviation and correlation coefficient of observed and model time series are mentioned above each panel.

atmospheric QBM has zonal wavelength comparable to that of the oceanic biweekly mode. We propose that the atmospheric QBM resonantly forces biweekly MRG waves in the ocean. In the upper ocean and at intermediate depths, the MRG waves have high amplitudes in the east ("eastern intensification"). The possible reasons for eastern intensification are also discussed in Section 5. Our main results are summarised and their possible implications mentioned in the concluding section.

\section{Observations and model}

\subsection{Observations}

A mooring with six subsurface current meters (Aanderaa RCM) was deployed at $0^{\circ}, 93^{\circ} \mathrm{E}$ in February 2000 by NIO. In December 2000, this mooring was redeployed with RCM's at nominal depths of 90, 245, 445, 950, 1970 and 3960 meters, and another mooring was installed at $0^{\circ}, 83^{\circ} \mathrm{E}$. The shallowest current meter at $83^{\circ} \mathrm{E}$ was at a mean depth of $385 \mathrm{~m}$, with similar instruments at 590, 1070 and $2100 \mathrm{~m}$; an ADCP mounted above the shallowest RCM did not return any data.
At all instruments, speed and direction are sampled 50 times in each recording interval, which is either one hour or two hours depending on depth. Each record is the average of these 50 values. Tidal frequencies are removed from the observed currents by taking a 49 hour running mean. The instruments also measure temperature, salinity and pressure. In this study we use daily de-tided observations from December 2000 to March 2002 from the $93^{\circ} \mathrm{E}$ mooring, and December 2000 to December 2001 from the $83^{\circ} \mathrm{E}$ mooring.

\subsection{Model}

We use the Modular Ocean Model 2.2 [Pacanowski, 1996] with Indian Ocean domain in this study. The model domain is $30^{\circ} \mathrm{S}-30^{\circ} \mathrm{N}$ and $30^{\circ} \mathrm{E}-110^{\circ} \mathrm{E}$, with a sponge layer at $30^{\circ} \mathrm{S}$. Horizontal resolution is about $1 / 3^{\circ}$ north of $5^{\circ} \mathrm{S}$. There are 19 levels in the vertical, six of which are in the top 100 meters. Model bottom topography is based on the $1 / 12^{\circ} \times$ $1 / 12^{\circ}$ resolution ETOPO5 data from the U.S. National Geophysical Data Center. Horizontal eddy diffusivity and viscosity are $2000 \mathrm{~m}^{2} \mathrm{~s}^{-1}$. Vertical mixing is based on the scheme of Pacanowski and Philander [1981]. Surface temperature and salinity are relaxed to the observed seasonal cycle of Levitus [1982].

The model is forced by surface winds from the scatterometer on board QuikSCAT [Liu, 2002], which are available since July 1999. The scatterometer estimates wind speed and direction with high accuracy [Chelton et al., 2001]. Three-day running mean wind fields, created from twicedaily $1 / 4^{\circ}$ gridded winds, have almost no gaps due to limited swath or rain. Wind stress was obtained from the three-day running mean winds by using a constant drag coefficient of 0.0013 . The model run forced by QuikSCAT wind stress is called the QuikSCAT simulation. A test run with an objectively interpolated daily gridded wind stress field created from QuikSCAT winds [Pegion et al., 2000] gives almost identical results. Initial conditions for the QuikSCAT simulation, in July 1999, are from a 15-year run of the model forced by daily wind stress obtained from NCEP reanalysis daily surface winds (the NCEP simulation). In another run (the seasonal run) the model was forced by the seasonally varying part of the QuikSCAT wind stress, obtained from the daily wind stress by removing all variability with periods shorter than 90 days.

\section{The biweekly mode in observations and model}

Variance preserving Blackmann-Tukey spectra [Chatfield, 1975] from the observations and from the QuikSCAT simulation are compared in Figure 2; the model $v$ is interpolated to daily instrument depth. The spectrum of observed $v$ from the shallowest current meter at $93^{\circ} \mathrm{E}$, whose mean depth is $106 \mathrm{~m}$, has a significant peak at 20-30 days, in addition to biweekly variability (Figure 2a). The two period bands seem to be merged in the spectra of model $v$ from the QuikSCAT simulation. Observed $v$ from the third and fourth instruments (mean depths $465 \mathrm{~m}$ and $965 \mathrm{~m}$ ) on the $93^{\circ} \mathrm{E}$ mooring shows a distinct biweekly peak in addition to variability on 20-60 day time scale (Figure 2b,c). Spectra at $83^{\circ} \mathrm{E}$ are qualitatively similar (Figure $2 \mathrm{~d}, \mathrm{e}, \mathrm{f}$ ). There are eight to ten power spectral estimates in the period range 20-40 days, depending on the length of the data. Some of the spectra therefore suggest that the 20-30 day variability in the observations is distinct from the 30-60 day variability (e.g. Figure 2e,f). The QuikSCAT simulation captures the biweekly variance reasonably well, but does not reproduce the 30-60 day variability. We do not understand the reason for this, but it may be related to inadequate model vertical resolution below the thermocline. We do not investigate 

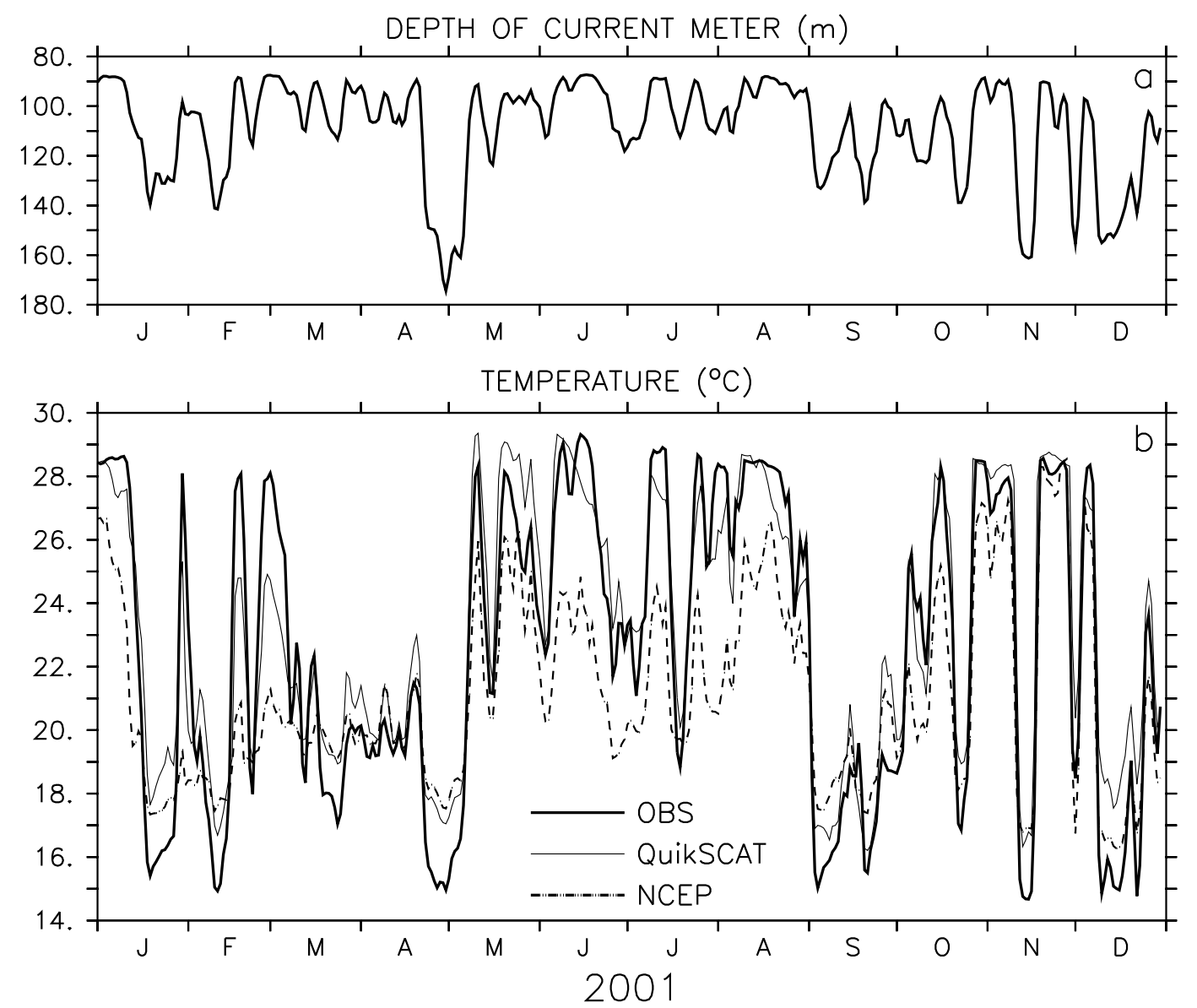

Figure 4. Time series of (a) daily mean depth of the uppermost current meter at $0^{\circ}, 93^{\circ} \mathrm{E}$; (b) temperature $\left({ }^{\circ} \mathrm{C}\right.$ ) measured by the instrument (bold), model temperature from the QuikSCAT simulation (thin) and NCEP simulation (dashed) interpolated to daily instrument depth.

the 30-60 day or 20-30 day variability in this paper. The biweekly mode is isolated using a 10-18 day Lanczos filter [Duchon, 1979] with 121 weights for further study.

Daily unfiltered $v$ for 2001 from the shallowest current meter at $93^{\circ} \mathrm{E}$ is shown in Figure 3a, together with daily meridional velocity at the mooring location from the QuikSCAT simulation, interpolated to the daily instrument depth; Figure 3(b-f) shows model-data comparisons of 1018 day filtered $v$ at $106 \mathrm{~m}, 265 \mathrm{~m}, 465 \mathrm{~m}, 965 \mathrm{~m}$ and 1970 $\mathrm{m}$. The model simulates the biweekly variability reasonably well at all depths at this location, as well as at $83^{\circ} \mathrm{E}$ (not shown). The biweekly oscillation is absent in the seasonal run (Figures 3b-f), demonstrating that it is forced by intraseasonal wind variability and not by dynamic instability. There is some intraseasonal variability of currents in the seasonal run, particularly at the uppermost level at $93^{\circ} \mathrm{E}$ (Figure 3b). However, the dominant periods of this variability, which must be due to instability, are longer than 20 days. The instability in the eastern EqIO has been discussed in Sengupta et al. [2001]. The NCEP simulation underestimates the observed biweekly variance; it captures the phase of the oscillations with some success (not shown), but the QuikSCAT simulation is more realistic. The importance of wind forcing is illustrated by means of a comparison of the QuikSCAT and NCEP simulations with temperature observations. The current meter moorings have no surface buoys.
Therefore the depth of the instruments can change rapidly as the mooring sways due to current drag (Figure 4a). The uppermost current meter at $93^{\circ} \mathrm{E}$ provides vertical "profiles" of thermocline temperature, which are reasonably well reproduced in the QuikSCAT simulation, but are poor in the NCEP simulation, particularly from mid-January to August (Figure 4b). The superior simulation of vertical stratification in the QuikSCAT simulation can be attributed to the weak variability of NCEP reanalysis surface winds relative

Table 1. Zonal wavelength estimated from the lag between observed time series of 10-18 day filtered $v$ at $465 \mathrm{~m}$ depth, $93^{\circ} \mathrm{E}$ and at $385 \mathrm{~m}$ depth, $83^{\circ} \mathrm{E}$.

\begin{tabular}{cc}
\hline Period & $\begin{array}{c}\text { Zonal wavelength } \\
(\mathrm{km})\end{array}$ \\
\hline 10 Jan - 7 Feb 2001 & 3400 \\
2 Mar - 22 Mar 2001 & 6100 \\
1 Jun - 5 Jul 2001 & 2100 \\
25 Jul - 30 Aug 2001 & 3100 \\
5 Sep - 15 Oct 2001 & 3100 \\
\hline
\end{tabular}




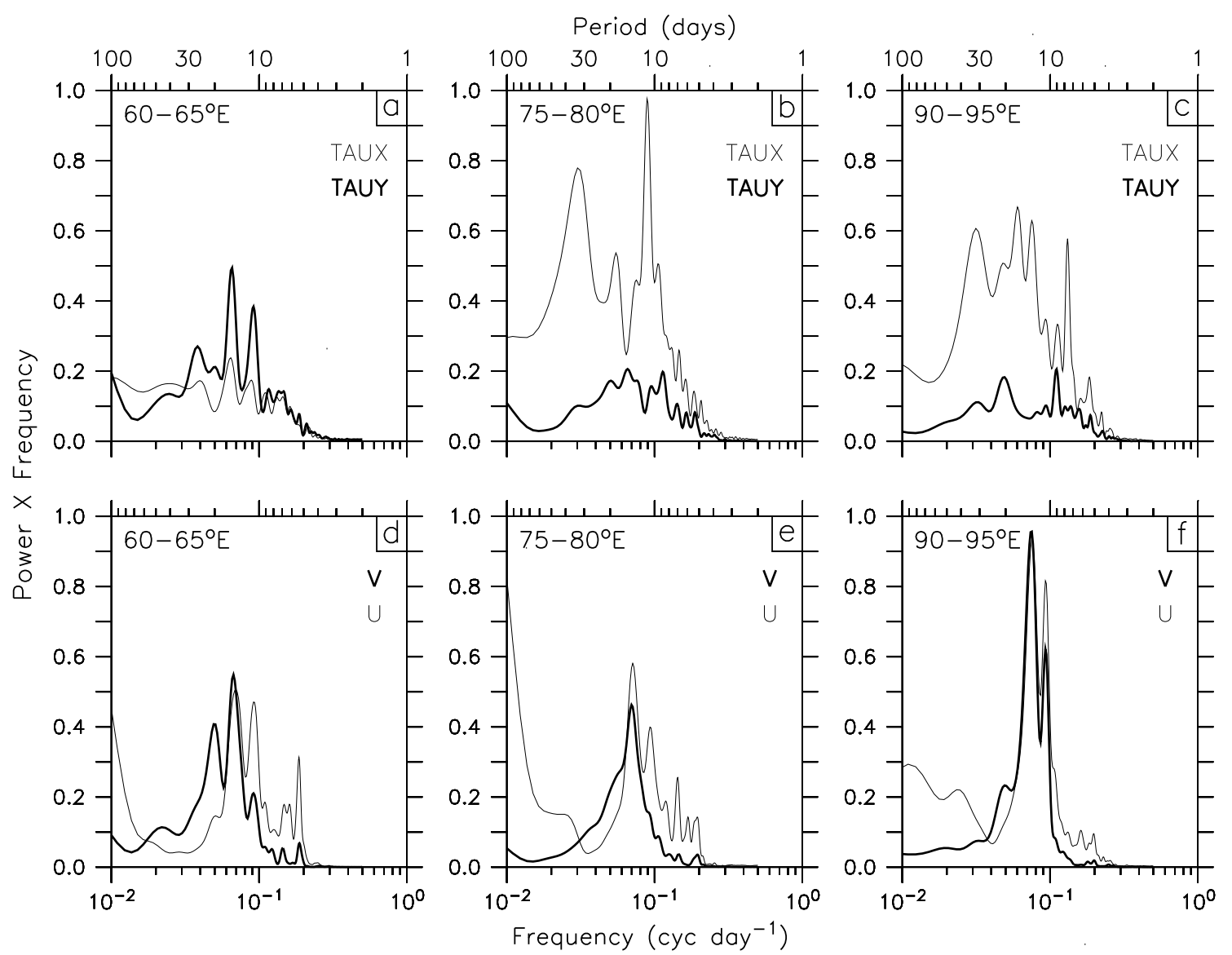

Figure 5. Variance preserving power spectra of January 2000-December 2001 QuikSCAT wind stress and model upper ocean response. (a) Spectra of $\tau_{x}$ (thin) and $\tau_{y}$ (bold) averaged over $1^{\circ} \mathrm{S}-1^{\circ} \mathrm{N}, 60-65^{\circ} \mathrm{E}$; (b) as in (a), but for $75-80^{\circ} \mathrm{E}$; (c) as in (a), but for $90-95^{\circ} \mathrm{E}$. (d) Model $50 \mathrm{~m} v$ (bold) averaged over $1^{\circ} \mathrm{S}-1^{\circ} \mathrm{N}, 60-65^{\circ} \mathrm{E}$ and model antisymmetric $u$ (thin), averaged over $3-5^{\circ} \mathrm{N}, 60-65^{\circ} \mathrm{E}$; (e) as in (d), but for $75-80^{\circ} \mathrm{E}$; (f) as in (d), but for $90-95^{\circ} \mathrm{E}$. Units are arbitrary, but identical for both $\tau_{x}$ and $\tau_{y}$ in (a), (b) and (c). Units of $v$ and $u$ are different, but identical for each parameter across panels (d), (e) and (f).

to QuikSCAT winds in the eastern EqIO [Goswami and Sengupta, 2003].

The intraseasonal variability of QuikSCAT wind stress is mainly in 10-60 day periods (Figure 5). $\tau_{y}$ in the west (Figure 5a) and $\tau_{x}$ in the central and eastern EqIO (Figure $5 \mathrm{~b}, \mathrm{c}$ ) have a peak at 10-20 day period. The spectra of model equatorial $v$ and off-equator $u$ are narrow relative to the spectra of wind stress (Figures $5 \mathrm{c}, \mathrm{d}, \mathrm{f}$ ), with a distinct biweekly maximum. Off-equator vertical velocity $(w)$ has a biweekly peak, with additional variability at 5-10 day periods (not shown).The spectra of ocean currents are consistent with the spatial structure of MRG waves, which have symmetric $v$ about the equator, and antisymmetric $u$ and $w$ with off-equator maxima.

\section{Space-time structure of the biweekly wave}

Comparison of the time series of 10-18 day filtered $v$ from the uppermost instrument at $83^{\circ} \mathrm{E}$ (depth $385 \mathrm{~m}$ ) with the observations at $465 \mathrm{~m}$ at $93^{\circ} \mathrm{E}$ shows that $v$ at $83^{\circ} \mathrm{E}$ generally lags $v$ at $93^{\circ} \mathrm{E}$, suggesting westward phase propagation. Oscillations of $v$ generally occur in groups of two-four cycles (this is discussed later); the lag between the two time series is not invariant in time over the full record, indicating that a range of wavelengths is associated with the biweekly wave. Therefore, different segments of the time series with constant lag are identified and the wavevector is estimated for each of these segments following Weisberg et al. [1979]. The zonal wavelengths range from 2100 to $6100 \mathrm{~km}$ (Table 1). The vertical wavelength is estimated in a similar manner from instrument pairs at the two locations (Table 2 ). The instruments pairs chosen are located at $385 \mathrm{~m}$ and $1070 \mathrm{~m}$ on the $83^{\circ} \mathrm{E}$ mooring, and $465 \mathrm{~m}$ and $965 \mathrm{~m}$ on the

Table 2. Vertical wavelength estimated from the lag between observed time series of 10-18 day filtered $v$ at (a) 465 $\mathrm{m}$ and $965 \mathrm{~m}$ at $93^{\circ} \mathrm{E}$ and (b) $385 \mathrm{~m}$ and $1070 \mathrm{~m}$ at $83^{\circ} \mathrm{E}$.

\begin{tabular}{cccc}
\hline \multicolumn{2}{c}{ a. $93^{\circ} \mathrm{E}$} & \multicolumn{2}{c}{ b. $83^{\circ} \mathrm{E}$} \\
\hline Period & $\begin{array}{c}\text { Vertical } \\
\text { Wavelength } \\
(\mathrm{m})\end{array}$ & Period & $\begin{array}{c}\text { Vertical } \\
\text { Wavelength } \\
(\mathrm{m})\end{array}$ \\
\hline 30 Aug-27 Sep & 4700 & 25 Feb-20 Mar & 3200 \\
2 Nov-27 Nov & 1400 & 10 Oct-3 Nov & 3200 \\
\hline
\end{tabular}




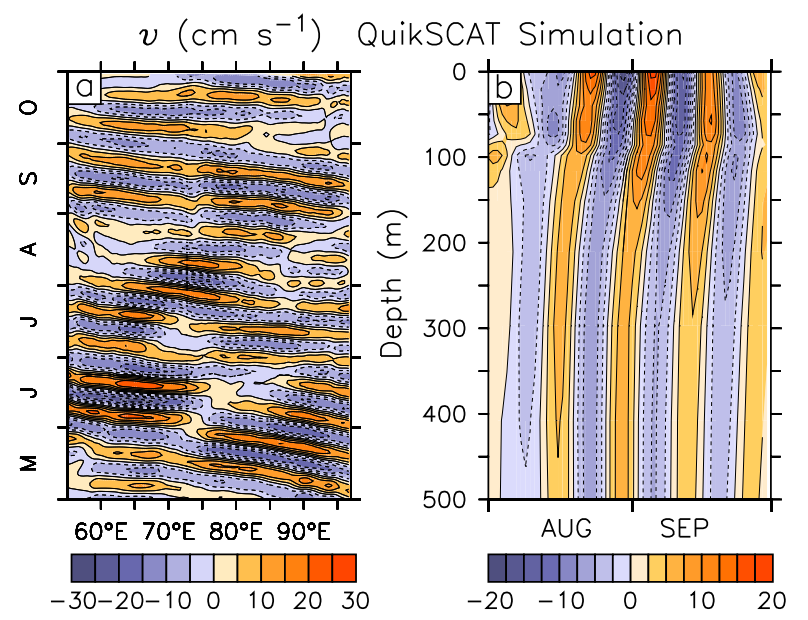

Figure 6. Propagation of the biweekly mode in summer 2001. (a) Time-longitude plot of model 10-18 day filtered $v$ at $50 \mathrm{~m}$ depth, averaged over $1^{\circ} \mathrm{S}-1^{\circ} \mathrm{N}$; the range of phase speed is $2.5-5.0 \mathrm{~m} \mathrm{~s}^{-1}$ westward, and group speed is about $1 \mathrm{~m} \mathrm{~s}^{-1}$ eastward; (b) Time-depth plot of model 10-18 day filtered $v$ at $0^{\circ}, 85^{\circ} \mathrm{E}$.

$93^{\circ} \mathrm{E}$ mooring. In general the $v$ time series at the shallower instrument lags that at the deeper instrument, showing upward phase propagation. However, there are occasions when the lag is unresolvable with daily data (i.e. it is less than one day, or effectively zero); there are also instances when the phase propagates downward, suggesting upward energy propagation due to bottom reflection. We have excluded such periods from the analysis.

Like the observations, the biweekly wave in the model has westward and generally upward phase propagation (Figure 6 ). There is a range of zonal wavelengths and associated phase speeds. Episodes of clear basinwide westward propagation are relatively infrequent. Group speed is eastward with a typical value of about $1 \mathrm{~m} \mathrm{~s}^{-1}$. The vertical scale of the wave below the thermocline is large (Figure 6b, Table 2) relative to the model vertical grid spacing, which is about $125 \mathrm{~m}$ at a depth of $500 \mathrm{~m}$. This might be the reason why the model is able to resolve the biweekly wave at deeper levels, although it has relatively coarse vertical resolution at these depths.

To determine the space-time characteristics of the biweekly wave, wavenumber-frequency spectra of currents at $50 \mathrm{~m}$ and $500 \mathrm{~m}$ from the QuikSCAT simulation are computed following the method of Wheeler and Kiladis [1999]. The symmetric component of $v$ and antisymmetric $u$ have large variance at 11-17 day period and wavelengths between $2200 \mathrm{~km}$ and $6000 \mathrm{~km}$ (Figure 7), centered at 14 days and $3000-4500 \mathrm{~km}$. The biweekly signal at $500 \mathrm{~m}$ depth has a similar range of zonal scales (Figure 8), in general agreement with the wavelength range determined from the filtered time series of observed $v$ (Table 1 ). The region of significant biweekly power lies on the dispersion curve of the MRG wave with a value of separation constant $c[$ Gill, 1982] equal to $2.1 \mathrm{~m} \mathrm{~s}^{-1}$, suggesting a mix of first and higher baroclinic modes. (The first baroclinic mode in the model has $c=$ $2.6 \mathrm{~m} \mathrm{~s}^{-1}$ ). There appear to be MRG waves with eastward phase propagation having a somewhat lower value of $c$ $\left(\sim 1.7 \mathrm{~m} \mathrm{~s}^{-1}\right)$ at $8-10$ day period (see Figure $2 \mathrm{~b}, \mathrm{c}$ ); however, the variance in this band is small relative to that at 10-18 days. The spectra of symmetric $v$ have significant power at 1000-1500 km wavelength and 20-30 day period (Figures $7 \mathrm{a}, 8 \mathrm{a})$, consistent with the secondary peak in some model $v$ frequency spectra.
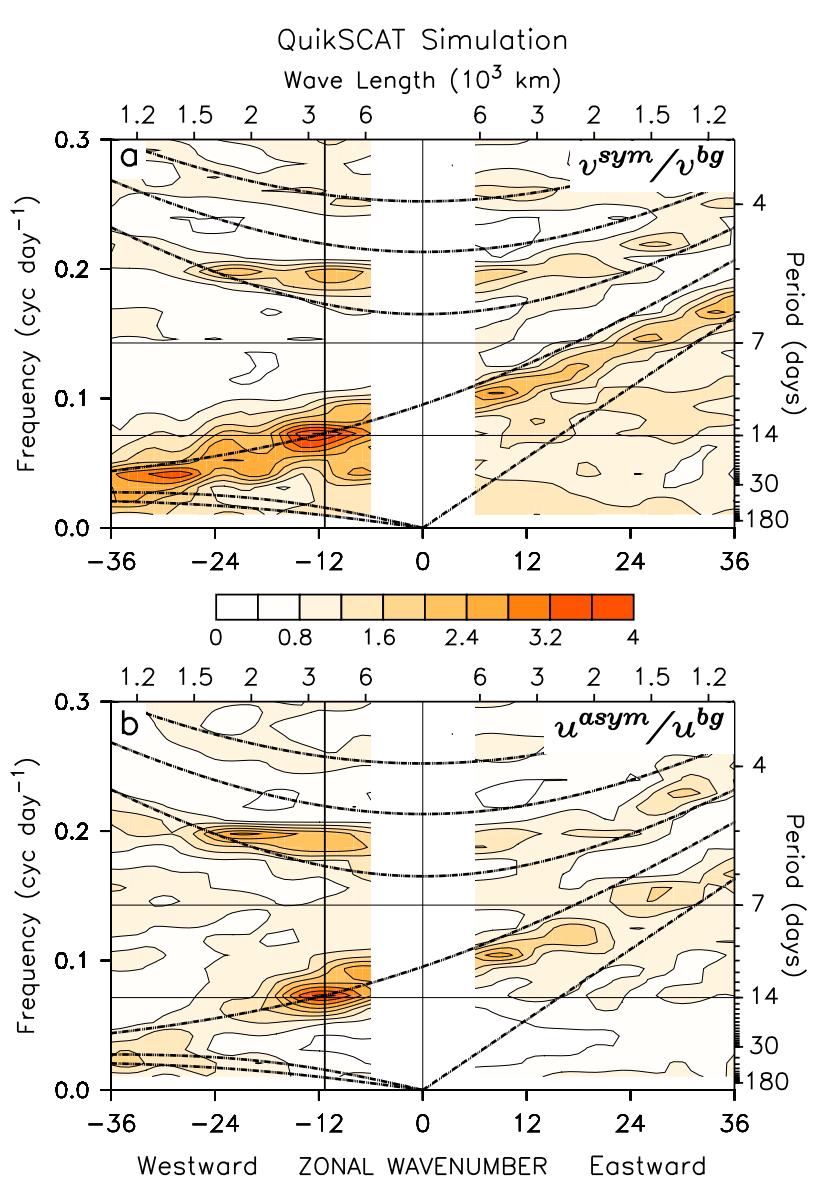

Figure 7. Zonal wavenumber-frequency power spectra of (a) symmetric component of $2^{\circ} \mathrm{S}-2^{\circ} \mathrm{N} v$ from QuikSCAT simulation at $50 \mathrm{~m}$ normalised by its background spectrum $v_{b g}$. The background spectrum is obtained by averaging the power of symmetric and antisymmetric $v$ and smoothing several times with a 1-2-1 filter in frequency and wavenumber (b) same as in (a) but for the anti-symmetric component of $3-5^{\circ} \mathrm{N} u$ at $50 \mathrm{~m}$. The dispersion curves for different classes of equatorial waves with separation constant $c=2.1 \mathrm{~m} \mathrm{~s}^{-1}$ are superimposed. Biweekly variability falls on the dispersion curve of the MRG wave. The vertical line marks (westward) wavelength of $3500 \mathrm{~km}$.

The characteristic horizontal structure of biweekly surface wind stress and ocean velocity fields is based on composites of 15 biweekly events from June to September 2000 and 2001, identified from 10-18 day filtered fields (Figure 9). Composites based on meridional wind stress show that the atmospheric quasi-biweekly mode is associated with symmetric $\tau_{y}$ with typical zonal scale (half-wavelength) of 15$20^{\circ}$ of longitude (Figures 9a,b,e,f). Composites based on wind stress curl (not shown) reveal that quasi-biweekly wind stress variability over the eastern $\mathrm{EqIO}$ consists of vortices of alternating sign centered on the equator, in agreement with Chen and Chen [1993] and Chatterji and Goswami [2004]. Periods of intense quasi-biweekly atmospheric activity are marked by symmetric $\tau_{y}$ that is strong on the western flank of the vortices, and antisymmetric $\tau_{x}$. The composite biweekly mode in the eastern (Figure $9 \mathrm{c}, \mathrm{d}$ ) and western (Figure $9 \mathrm{~g}, \mathrm{~h}$ ) ocean at $\sim 100 \mathrm{~m}$ depth has the structure of an MRG wave with half-wavelength of about $20^{\circ}$. The average interval between the dates used for the eastern and western composites is about 9 days, corresponding to westward propagation at $4 \mathrm{~m} \mathrm{~s}^{-1}$. The ocean current composites suggest 

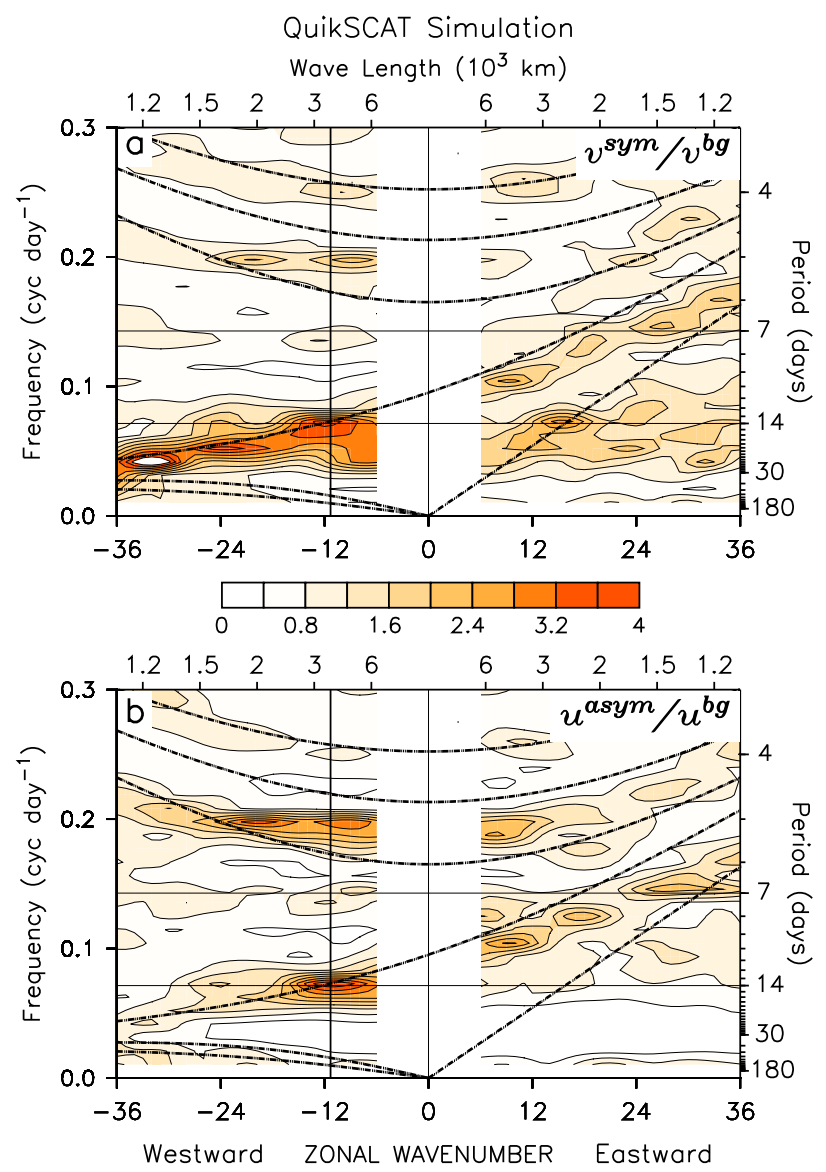

Figure 8. Same as in Figure 7, but for $v$ and $u$ at $500 \mathrm{~m}$.

that the zonal and meridional scale of the wave is somewhat larger in the east than in the west. The difference in meridional scale is consistent with the different stratification of the upper ocean in the east and west. The vertical velocity associated with the composite biweekly mode has maximum amplitude of 2-3 meters per day. The $w$ field is antisymmetric about the equator, with amplitude maxima located at $2-3^{\circ}$ latitude, in keeping with theory. The composite horizontal structure at $500 \mathrm{~m}$ depth (Figure 10) has qualitatively similar characteristics. The composite structure in the latitude-depth plane (Figure 11) consists of deep upwelling/downwelling on either side of the equator, connected by cross-equatorial meridional flow.

\section{Forcing mechanism and "eastern intensification" of the biweekly wave}

We have established that the biweekly MRG wave in the ocean is forced by intraseasonal variability of wind stress, and that the dominant zonal wavelength is $3000-4500 \mathrm{~km}$ (Figures 7, 8). The zonal scale of the atmospheric QBM, estimated in the literature from analysed winds at $850 \mathrm{hPa}$ and higher levels, is reported to be $6000 \mathrm{~km}$. However, the zonal scale of the biweekly surface wind forcing is considerably smaller. Meridional wind stress can effectively excite MRG waves, because these waves have symmetric $v$ and antisymmetric $u$ fields [Wunsch and Gill, 1976]. We find that the zonal scale of meridional wind stress at the surface associated with the atmospheric QBM is $3000-4500 \mathrm{~km}$ (Figure 12). Biweekly variability of symmetric $\tau_{y}$ over the central and eastern EqIO (but not in the western EqIO) is associated with QBM vortices centred near the equator both in summer and winter, as discussed before [Chatterji and Goswami, 2004]. The composites shown in Figure 9 suggest that the zonal wavelength of $\tau_{y}$ is only $3000-4500$ $\mathrm{km}$, not $6000 \mathrm{~km}$, because the magnitude of $\tau_{y}$ is significant only on the western flanks of the vortices. Based on these results we propose that the atmospheric QBM resonantly excites the biweekly wave in the Indian Ocean, i.e., the period, zonal wavelength and westward propagation speed of the ocean response matches that of the forcing, and corresponds approximately to the characteristics of free MRG waves. It is likely that the QBM excites biweekly waves in the west Pacific as well. An MRG wave with westward phase propagation, $4000 \mathrm{~km}$ zonal wavelength and 14 day period has been reported in the upper west Pacific from TOGA COARE observations [Zhu et al., 1998]. According to the authors, this wave was generated by $\tau_{y}$ forcing associated with an atmospheric Rossby wave.

Biweekly variability of equatorial $v$ in the upper ocean is largest in the far eastern EqIO, although the variability of 10-18 day $\tau_{y}$ is largest in the west (see Figure 5). Broadly speaking, some form of eastern intensification might be expected because MRG waves have eastward group speed. The energy in biweekly MRG waves at a given longitude is due to local forcing as well as energy arriving from the west. Note that the energy density of MRG waves need not be highest in the east if there are reflected equatorially trapped waves carrying biweekly energy back to the west. However, there are no free waves in the tropical ocean with periods between $\sim 1$ week and $\sim 1$ month and westward group speed [Gill, 1982]. Model results show that coastally trapped waves with biweekly period are generated when biweekly MRG waves are incident on an eastern boundary. In the deep ocean, biweekly $v$ variability at the equator is related to $v$ variability at higher latitudes within $200 \mathrm{~km}$ of the eastern boundary (Figure 13, 14b), as well as around the Chagos ridge at $73^{\circ} \mathrm{E}$. (The relation between equatorial MRG waves and coastally trapped biweekly waves is not as clear in the upper ocean, where coastal waves can be forced by surface wind stress variability.) Figure 14a shows that biweekly $\tau_{y}$ is episodic. As mentioned earlier, the forcing generates episodic MRG waves in the ocean consisting of groups of two to four waves. There is no apparent seasonality in the amplitude of the forcing or the ocean response, although the record is too short to be conclusive. Based on these results, we propose that (1) a part of the energy of the MRG wave can escape to higher latitudes via coastal Kelvin waves and (2) eastern intensification arises essentially because the MRG wave has eastward group speed and because there are no free equatorially trapped waves with westward group speed in the 10-18 day period range. Therefore, the biweekly MRG wave cannot "reflect" off an eastern boundary, and the biweekly coastal Kelvin wave does not radiate Rossby waves.

\section{Discussion}

Recent observations at $0^{\circ}, 83^{\circ} \mathrm{E}$ and $0^{\circ}, 93^{\circ} \mathrm{E}$ in the Indian Ocean suggest that meridional current has subseasonal variability on three distinct time scales - 10-20 days, 20-30 days and 30-60 days (Figure 2). The biweekly variability is episodic and present throughout the year with no clear seasonality. There are episodes lasting one to two months when the phase difference between 10-18 day filtered $v$ at $\sim 500 \mathrm{~m}$ depth on the two moorings is relatively constant, suggesting the presence of wave groups with zonal wavelength varying from $2000 \mathrm{~km}$ to $6000 \mathrm{~km}$; phase propagates westward. Phase lags between $v$ at different depths $(\sim 500 \mathrm{~m}$ and $\sim 1000 \mathrm{~m}$ ) on each of the moorings occasionally implies upward phase propagation; the vertical wavelength during these episodes varies from $1400 \mathrm{~m}$ to $5700 \mathrm{~m}$. 
Wind stress vectors and $\tau_{y}$ (Eastern EqlO composite)
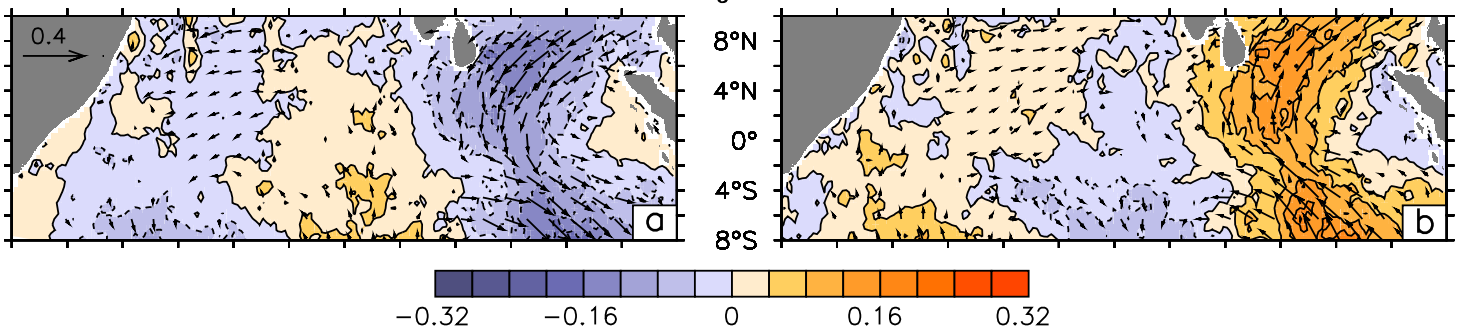

Current vectors and $w$ at $100 \mathrm{~m}$ (Eastern EqlO composite)

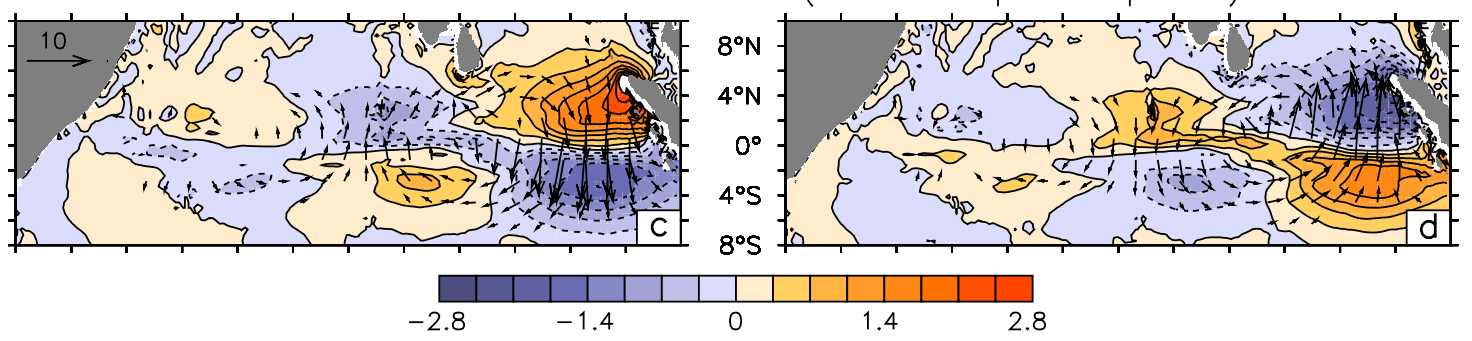

Wind stress vectors and $\tau_{y}$ (Western EqlO composite)
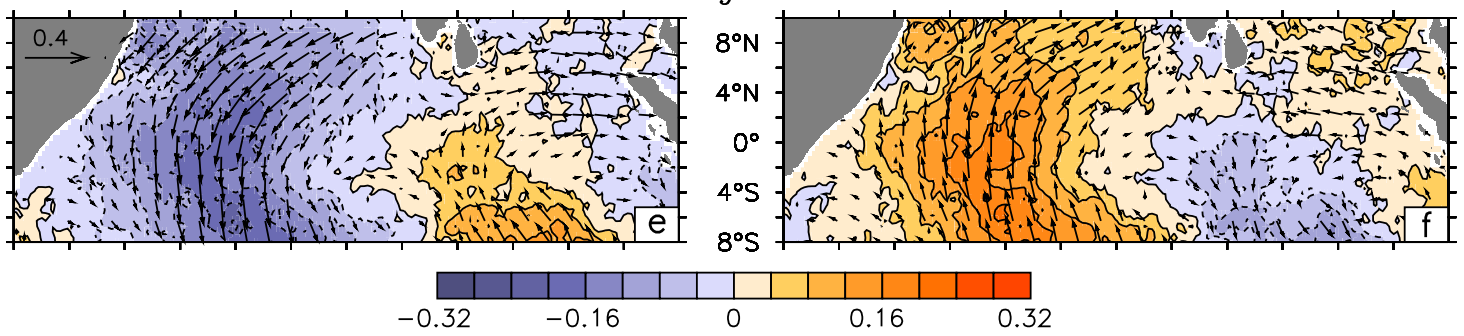

Current vectors and $w$ at $100 \mathrm{~m}$ (Western EqIO composite)

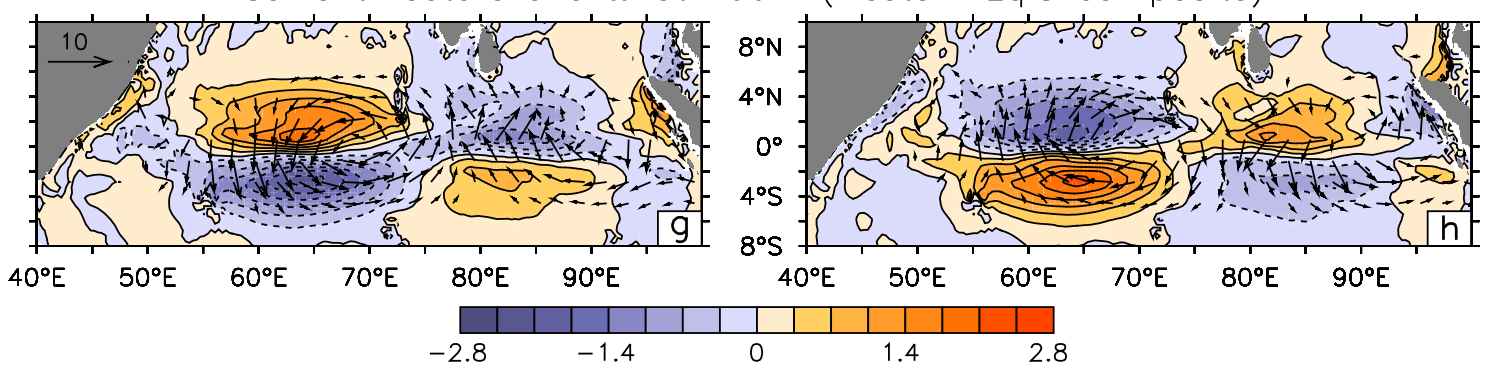

Figure 9. Composite horizontal structure of biweekly wind stress and model upper ocean velocity. (a,b) Meridional wind stress (dyn $\mathrm{cm}^{-2}$; contours with negative values shaded) and wind stress vector (dyn $\mathrm{cm}^{-2}$ ) composites based on dates of maximum negative (left) and positive (right) $\tau_{y}$ averaged over $5^{\circ} \mathrm{S}-5^{\circ} \mathrm{N}, 85-90^{\circ} \mathrm{E}$; (e,f) as in $(\mathrm{a}, \mathrm{b})$, but for $55-60^{\circ} \mathrm{E}$; (c,d) composite vertical velocity ( $\mathrm{m}$ day ${ }^{-1}$; contours with negative values shaded) and current vectors at $\sim 100 \mathrm{~m}$ depth $\left(\mathrm{cm} \mathrm{s}^{-1}\right)$, based on dates of maximum southward (left) and northward (right) meridional volume transport across the equator in the upper 100 meters between $90-95^{\circ} \mathrm{E} ;(\mathrm{g}, \mathrm{h})$ as in $(\mathrm{c}, \mathrm{d})$, but for $60-65^{\circ} \mathrm{E}$.
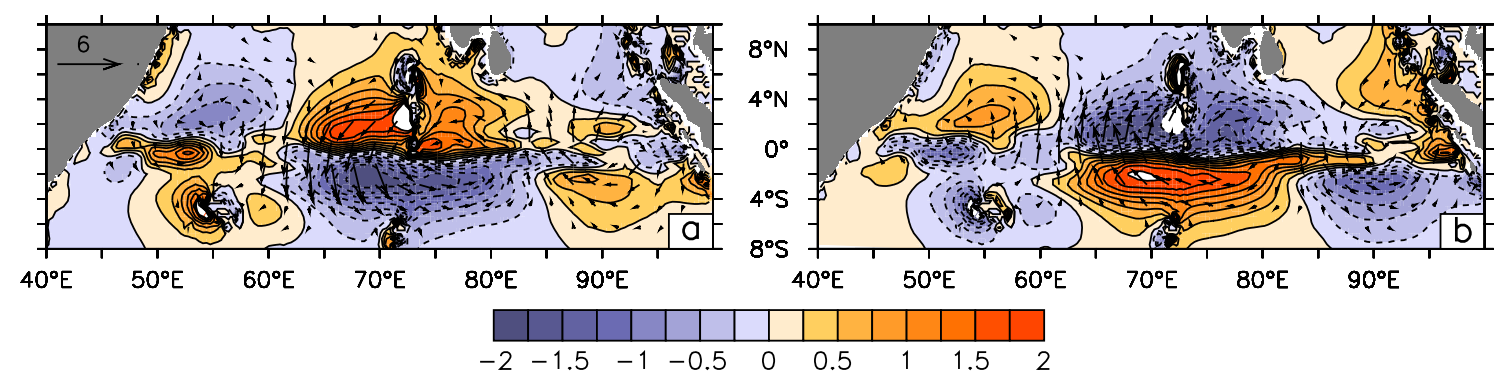

Figure 10. Composite horizontal structure of biweekly wave at $\sim 500 \mathrm{~m}$. Composite vertical velocity at $470 \mathrm{~m}$ depth $\left(\mathrm{m}\right.$ day ${ }^{-1}$; contours with negative values shaded) and current vectors at $530 \mathrm{~m}$ depth $\left(\mathrm{cm} \mathrm{s}^{-1}\right)$; the composites are based on dates of maximum (a) southward and (b) northward meridional volume transport across the equator, between $450-550 \mathrm{~m}$ and $60-65^{\circ} \mathrm{E}$. 

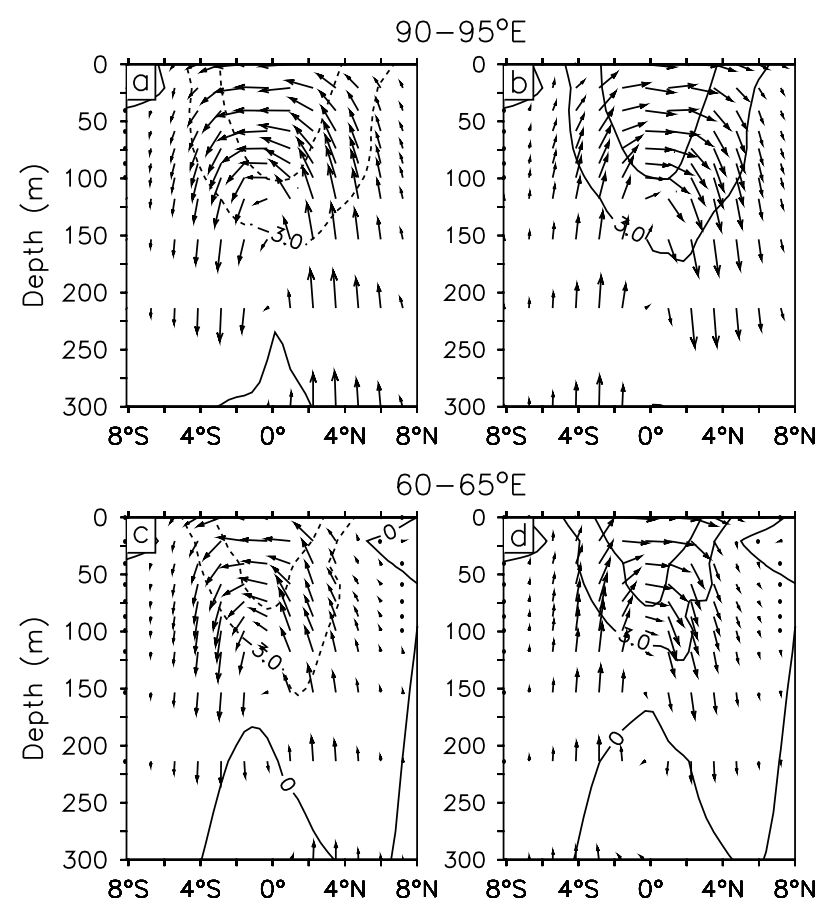

Figure 11. Composite vertical structure of the biweekly wave. Meridional velocity ( 0,3 and $9 \mathrm{~cm} \mathrm{~s}^{-1}$ contours) and current vectors in the latitude-depth plane, averaged over $(\mathrm{a}, \mathrm{b}) 90-95^{\circ} \mathrm{E}$ and $(\mathrm{c}, \mathrm{d}) 60-65^{\circ} \mathrm{E}$, in the southward (left) and northward (right) phases of the wave. Vertical velocity has been multiplied by 6,000 to preserve vector orientation. Composites are based on the same dates as the current composites in Figure 9.

A model forced by QuikSCAT winds simulates the biweekly variability well because the wind forcing is accurate. The simulation does not suffer at deeper depths, possibly because the vertical scale of the biweekly mode is large relative to model vertical resolution. However, the model fails to produce the observed 30-60 day variability. Space-time spectra of unfiltered model velocity fields, as well as summer

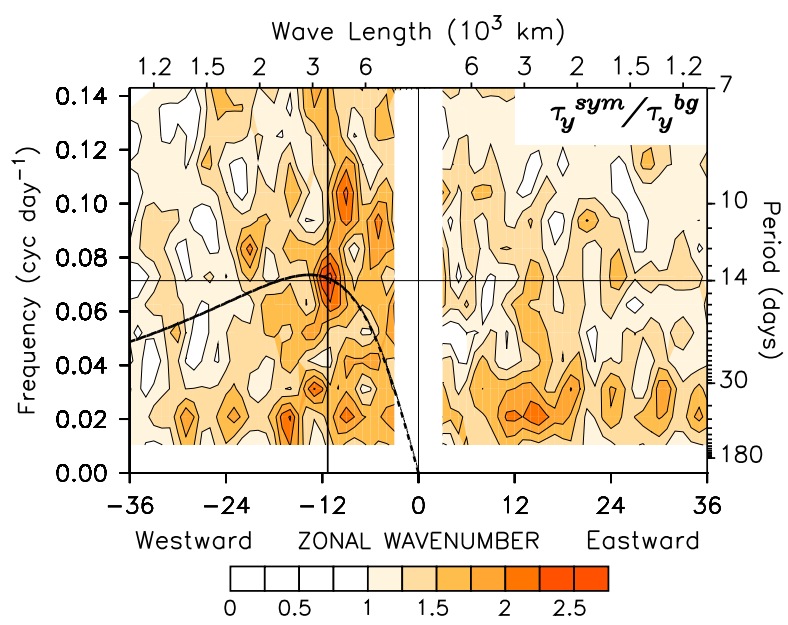

Figure 12. Zonal wavenumber-frequency power spectra of symmetric component of $5^{\circ} \mathrm{S}-5^{\circ} \mathrm{N} \tau_{y}$ normalised by its background spectrum; July 1999-December 2002. The dispersion curve of the first meridional mode $(n=1)$ Rossby wave with $c=15 \mathrm{~m} \mathrm{~s}^{-1}$ is superposed. The full vertical line marks wavelength of $3500 \mathrm{~km}$
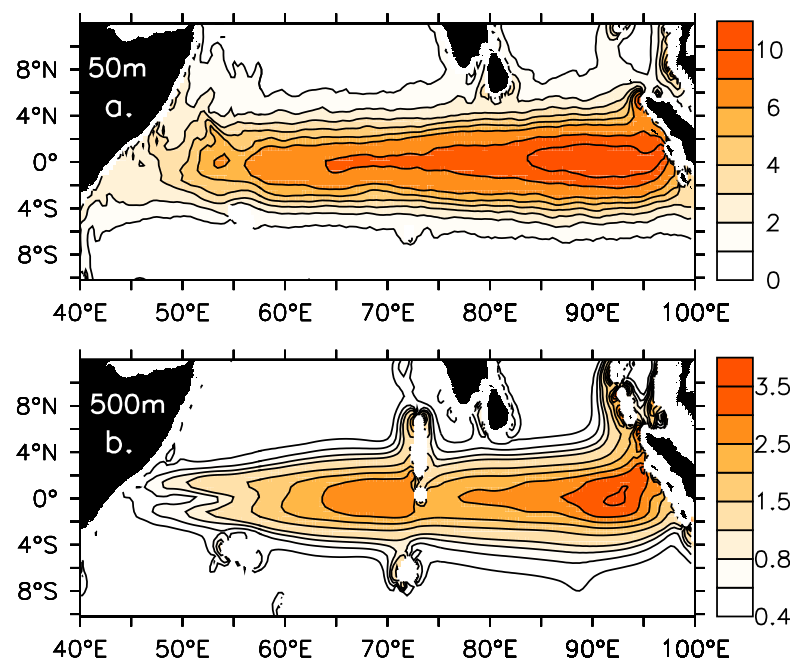

Figure 13. Standard deviation of 10-18 day filtered $v$ $\left(\mathrm{cm} \mathrm{s}^{-1}\right)$ from the QuikSCAT simulation at (a) $50 \mathrm{~m}$ (b) 500 m; July 1999-December 2002.

composites based on filtered fields (Figure 9), show that the biweekly mode is a mixed Rossby-gravity wave. The largest variance of model symmetric $v$ and antisymmetric $u$ is at 14 day period and 3000-4500 km zonal wavelength (Figures 7, 8 ). Biweekly variance lies approximately on the MRG dispersion curve with $c=2.1 \mathrm{~m} \mathrm{~s}^{-1}$. This value of $c$ suggests the presence of first and higher baroclinic modes. The presence of higher modes is consistent with vertical propagation seen in the Hovmoller plot (Figure 6b). Energy in the upper $2000 \mathrm{~m}$ propagates eastward and generally downward, though there are indications of upward energy propagation in both data and model. Biweekly variability is enhanced in the far eastern region and just west of topographic features, such as the ridge at $73^{\circ} \mathrm{E}$ (Figure 13), where the MRG wave generates biweekly waves trapped along the topography (Figure 14b). We propose that eastward intensification
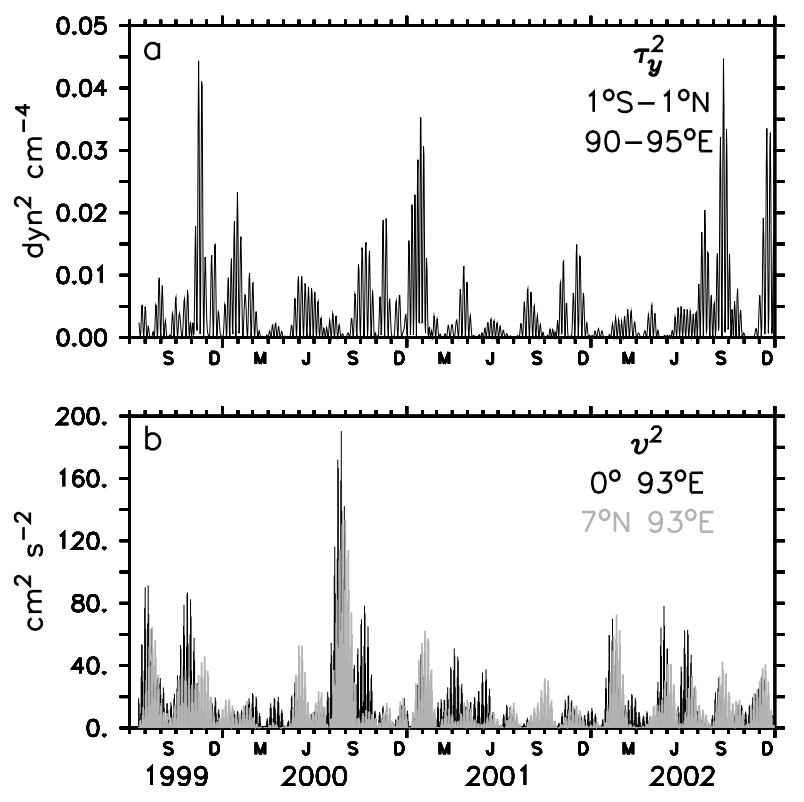

Figure 14. Time series of square of 10-18 day filtered (a) meridional wind stress averaged over $1^{\circ} \mathrm{S}-1^{\circ} \mathrm{N}$ and $90-95^{\circ} \mathrm{E}(\mathrm{b})$ meridional velocity at $0^{\circ}, 93^{\circ} \mathrm{E}$ (black) and $7^{\circ} \mathrm{N}, 93^{\circ} \mathrm{E}$ (grey). 
arises partly because there are no allowed equatorial waves with biweekly period and westward group speed.

The quasi-biweekly mode in the atmosphere at $850 \mathrm{hPa}$ and higher levels has a zonal wavelength of about 6000 km [Chen and Chen, 1993; Chatterji and Goswami, 2004]. These studies have shown that atmospheric QBM east of $65^{\circ} \mathrm{E}$ is often associated with a vortex centred around the equator. This is crucial for the existence of substantial symmetric meridional wind stress near the equator (Figure 9), which is the main forcing for oceanic MRG waves. The zonal wavelength of biweekly $\tau_{y}$, however, is $3000-4500 \mathrm{~km}$ (Figures 9,12 ), because meridional surface wind stress is strong only on the western flank of the vortex. We conclude, therefore, that the quasi-biweekly oscillations of surface winds resonantly excite biweekly MRG waves in the Indian Ocean. The biweekly wave is distinct from the 26 day wave reported in the western EqIO [Luyten and Roemmich, 1982] that is probably generated by dynamic instability of ocean currents [Kindle and Thompson, 1989]. In this connection, it is interesting that the observations (and the model) show some evidence of 20-30 day $v$ variability in the eastern EqIO.

We have established that biweekly variability in the equatorial ocean is due to wind forced MRG waves. However, our discussion of the generation mechanism and energetics of the biweekly waves is somewhat incomplete at this stage. Although we find that the quality of the wind forcing is important, we do not know to what extent our results are model dependent. For instance, a model with different mixing parameterization might distinguish the biweekly variability from 20-30 day variability in a more satisfactory manner (Figure 2). We have not examined the possibility, suggested by symmetry considerations, that antisymmetric $\tau_{x}$ might generate MRG waves. Further work is needed on the generation mechanism, vertical energy propagation (including the possibility of bottom reflection), and energetics of eastward intensification of the biweekly mode.

Finally, we note that the biweekly upwelling/downwelling reported here might have implications for the biogeochemistry of the Indian Ocean. Eastward equatorial jets in spring and fall, forced by westerly winds [Knox, 1976], lead to downwelling and a deep thermocline in the eastern Indian Ocean [Wyrtki, 1973]. The appearance of sustained easterly winds in the EqIO during strong "dipole" episodes such as those of 1961, 1994 or 1997 can drive upwelling off the coast of Sumatra as well as at the equator [Murtugudde et al., 2000], associated with high chlorophyll concentrations in the east [Murtugudde et al., 1999]. We have presented evidence that upwelling in the EqIO is not confined to dipole events or to the eastern basin - episodic deep upwelling and downwelling associated with the biweekly mode is present throughout the year all along the EqIO, except in the far west. The maximum upwelling speed in individual MRG waves can be as large as $6-8 \mathrm{~m} \mathrm{day}^{-1}$. Since upwelling followed by mixing is an irreversible process, the biweekly mode is likely to influence the vertical distribution of temperature, nutrients and chlorophyll in the equatorial Indian ocean. The possibility that the biweekly mode has an influence on meridional heat transport in the Indian Ocean [see Loschnigg and Webster, 2000] is also worth examining.

Acknowledgments. We thank Jay McCreary, Toru Miyama, and Bhupen Goswami for many useful discussions, and the members of CLIVAR AAMP for comments. Reviewers of a previous short version of this paper gave several useful suggestions. DS thanks Department of Science and Technology, New Delhi for funding. DS and VSNM would like to acknowledge long-term financial support from Department of Ocean Development, New Delhi, which made this work possible. VSNM thank the Director, NIO for support, and all members of the mooring team as well as officers and crew of ORV Sagar Kanya. The QuikSCAT wind data were obtained from the ftp site (ftp://podaac.jpl.nasa.gov/pub/ocean_wind/quikscat) of Physical Oceanography Distributed Active Archive Center (PO.DAAC), NASA Jet Propulsion Laboratory, Pasadena, U.S.A. This is NIO contribution number 3918 .

\section{References}

Chatfield, C. (1975), The analysis of time series: Theory and practice, 263 pp., Chapman and Hall, London.

Chatterji, P., and B. N. Goswami (2004), Structure, Genesis and Scale Selection of the Tropical Quasi-Biweekly mode, Quart. J. Roy. Meteorol. Soc., 130(599), 1171-1194.

Chen, T.-C., and J.-M. Chen (1993), The 10-20-Day mode of the 1979 Indian monsoon: Its relation with the time variation of monsoon rainfall, Mon. Weather Rev., 121, 2465-2482.

Duchon, C. E. (1979), Lanczos filter in one and two dimensions, J. Appl. Meteorol., 18, 1016-1022.

Gill, A. E. (1982), Atmosphere-Ocean Dynamics, Academic Press, New York.

Goswami, B. N., and D. Sengupta (2003), A Note on the Deficiency of NCEP/NCAR Reanalysis Surface Winds over the Equatorial Indian Ocean, J. Geophys. Res., 108(C4), 3124 doi:10.1029/2002JC001497.

Goswami, B. N., D. Sengupta, and S. Kumar (1998), Intraseasonal oscillations and interannual variability of surface winds over the Indian monsoon region, Proc. Ind. Acad. Sci, 107(1), $45-64$.

Kalnay, E., et al. (1996), The NCEP/NCAR 40-year ranalysis project, Bull. Amer. Meteorol. Soc., 77, 437-471.

Kindle, J. C., and J. D. Thompson (1989), The 26- 50 days oscillation in the western Indian Ocean: Model Results, J. Geophys. Res., 94, 4721-4736.

Knox, R. (1976), On a long series of measurements of Indian Ocean equatorial currents near Addu Atoll., Deep-Sea Res. 23, 211-221.

Krishnamurti, T. N., and P. Ardunay (1980), The 10 to 20 day westward propagating mode and "breaks in the monsoons", Tellus, 32, 15-26.

Krishnamurti, T. N., D. K. Oosterhof, and A. V. Mehta (1988), Air-sea interaction on the time scale of 30 to 50 days, J. Atmos. Sci., 45, 1304-1322.

Levitus, S. (1982), Climatological atlas of the world ocean, NOAA Prof. Pap, U. S. Govt. Print. Off., Washington, D.C.

Loschnigg, J., and P. J. Webster (2000), A coupled oceanatmosphere system of SST modulation for the Indian Ocean, J. Climate, 13, 3342-3360.

Luyten, J. R., and D. H. Roemmich (1982), Equatorial currents at semiannual period in the Indian Ocean, J. Phys. Oceanogr., 12, 406-413.

Madden, R. A., and P. R. Julian (1972), Description of globalscale circulation cells in the tropics with a 40-50 day period, J. Atmos. Sci., 29, 1109-1123.

Madden, R. A., and P. R. Julian (1994), Observations of the 4050 day tropical oscillation: A review, Mon. Weather Rev., 122, 814-837.

Masumoto, Y., V. S. N. Murty, M. Jury, M. J. McPhaden, P. Hacker, J. Vialard, R. Molcard, and G. Meyers (2002), Tropical Indian Ocean mooring array: Present status and future plans., Unpublished manuscript, Available at http://oceanpartners.org/POGO-4 docs/IndianOceanArrays.pdf.

Matsuno, T. (1966), Quasi-geostrophic motions in the equatorial area, J. Meteorol. Soc. Jap., 44, 25-43.

McPhaden, M. J. (1982), Variability in the central equatorial Indian Ocean Part I: Ocean dynamics, J. Mar. Res., 40, 157-176.

Murtugudde, R., S. Signorini, J. Christian, A. Busalacchi, C. McClain, and J. Picaut (1999), Ocean color variability of the tropical Indo-Pacific basin observed by SeaWiFS during 1997 98., J. Geophys. Res., 104, 18,351-18,366.

Murtugudde, R., J. McCreary, and A. Busalacchi (2000), Oceanic processes associated with anomalous events in the Indian Ocean with relevance to 1997-98., J. Geophys. Res., 105, 32953306.

Murty, V. S. N., A. Suryanarayana, M. Sarma, V. Tilvi, V. Fernando, G. Nampoothiri, A. Sardar, D. Gracias, and S. Khalap (2002), First results of Indian current meter moorings along the equator: Vertical current structure variability at equator, $93^{\circ}$ E during February-December 2000, 1, pp. 25-28, Proc. 6th Pan Ocean Remote Sensing Conference, PORSEC 2002, Bali, Indonesia. 
Pacanowski, R. C. (1996), MOM2 Version 2.0(beta): Documentation, user's guide and reference manual. GFDL Ocean Technical Report 3.2, Geophysical Fluid Dynamics Laboratory, Princeton NJ.

Pacanowski, R. C., and S. G. H. Philander (1981), Parameterization of vertical mixing in numerical models of tropical oceans, J. Phys. Oceanogr., 11, 1443-1451.

Reppin, J., F. Schott, J. Fischer, and D. Quadfasel (1999), Equatorial currents and transports in the upper central Indian Ocean, J. Geophys. Res., 104, 15,495-15,514.

Reverdin, G., and J. Luyten (1986), Near-surface meanders in the equatorial Indian Ocean, J. Phys. Oceanogr., 16, 1088-1100.

Schott, F., and J. P. McCreary (2001), The monsoon circulation of the Indian Ocean, Prog. Oceanogr., 51, 1-123.

Schott, F., J. Reppin, J. Fischer, and D. Quadfasel (1994), Currents and transports of the monsoon current south of Sri Lanka, J. Geophys. Res., 99, 25,127-25,141.

Sengupta, D., R. Senan, and B. N. Goswami (2001), Origin of Intraseasonal variability of circulation in the tropical central Indian Ocean, Geophys. Res. Lett., 28(7), 1267-1270.

Sikka, D. R., and S. Gadgil (1980), On the maximum cloud zone and the ITCZ over Indian longitudes during the southwest Monsoon, Mon. Weather Rev., 108, 1840-1853.

Tsai, P. T. H., J. J. O'Brien, and M. E. Luther (1992), The 26-day oscillation observed in the satellite sea surface temperature measurements in the equatorial western Indian Ocean, J. Geophys. Res., 97, 9605-9618.
Weisberg, R. H., A. Horigan, and C. Colin (1979), Equatorially trapped Rossby-gravity wave propagation in the Gulf of Guinea, J. Mar. Res., 37, 67-86.

Wheeler, M., and G. N. Kiladis (1999), Convectively Coupled Equatorial Waves: Analysis of Clouds and Temperature in the Wavenumber-Frequency Domain, J. Atmos. Sci., 56, 374-399.

Wunsch, C., and A. E. Gill (1976), Observations of equatorially trapped waves in Pacific sea level variations, Deep-Sea Res., 23, 371-390

Wyrtki, K. (1973), An equatorial jet in the Indian Ocean, Science, 181, 262-264.

Yasunari, T. (1981), Structure of an Indian summer monsoon system with around 40-day period, J. Meteorol. Soc. Japan, 59, 336-354.

Zhu, Z. H., A. Kaneko, N. Gohda, H. Inaba, K. Kutsuwada, and M.-H. Radenac (1998), Observation of mixed Rossby-gravity waves in the western equatorial Pacific, J. Oceanogr., 54, 133141 .

D. Sengupta and R. Senan, Centre for Atmospheric and Oceanic Sciences, Indian Institute of Science, Bangalore, 560012, India. (dsen@caos.iisc.ernet.in, retish@caos.iisc.ernet.in)

V. S. N. Murty and V. Fernando, Physical Oceanography Division, National Institute of Oceanography, Dona Paula, Goa, 430004, India. (vsnmurty@darya.nio.org, vijayan@darya.nio.org) 